\title{
Influence of Educational background in Pathological Stage and Treatment Modalities in Iranian Breast Cancer Patients: A Retrospective Single Center Study
}

Amir Shahram Yousefi Kashi ( $\sim$ shahpoo2002@yahoo.com )

Shahid Beheshti Univeristy of Medical Sciences https://orcid.org/0000-0002-0787-2480

\section{Research Article}

Keywords: Breast cancer, Educational background, Pathological stage, Treatment modalities

Posted Date: November 9th, 2020

DOI: https://doi.org/10.21203/rs.3.rs-61929/v2

License: (1) (1) This work is licensed under a Creative Commons Attribution 4.0 International License. Read Full License 


\section{Abstract}

Background: Breast cancer is the most frequent diagnosed visceral cancer with 13400 new cases annually in Iranian women. There are a few studies in the west countries that indicates that breast cancer patients with higher educational background had better prognosis than patients with lower education background.

Objectives: In a retrospective single center study we compared educational background and its relationship to pathological stage and their treatment modalities among 3010 breast cancer patients.

Methods: Medical records of 3010 patients with breast cancer from database at Cancer Research Center of the Shahid Beheshti University of Medical Sciences were reviewed and univariate logistic regression analysis was used for association between education background and its relationship to pathological breast cancer stage and treatment modalities.

Results: The average age at diagnosis was 49.1 years \pm 11.6 years. The proportion of breast cancer patients' levels of education were $4.2 \%$ illiterate, $7.8 \%$ primary school, $7.5 \%$ middle school, $21.8 \%$ high school and diploma, $18.6 \%$ university and above and $40.1 \%$ unspecified.

Based on univariate logistic regression analysis, the illiterate group had $65.1 \%$ of early stage breast cancer (stage I and stage II), and the university and above group had $73.4 \%$ of early stage breast cancer (p-value<.001). The rate of receiving chemotherapy, radiotherapy and endocrine therapy was in the illiterate group $35.7 \%, 42.1 \%, 50 \%$ and was in the university and above group $93.7 \%, 64.3 \%$ and $71.1 \%$ respectively(p-value<.001). The rate of breast conserving surgery (BCS) in the illiterate group, the primary school, the middle school, the high school and diploma, and the university and above group was $15.1 \%$, $18 \%, 16.3 \%, 42.5 \%$, and $73.2 \%$ respectively ( $p$-value $<.001$ ).

Conclusions: The findings of this study showed that education background have a significant impact on pathological staging and the selection of treatment modalities.

\section{Introduction}

Among Iranian women, breast cancer is the most frequent diagnosed visceral cancer with second cause of death due to cancer based on the Cancer Registry System (1).

There are 13400 new cases of breast cancer annually with incidence rate of 32 in 100000 in Iranian women. In Iran, breast cancer diagnosed teen years earlier than most developed countries, therefore, we had a major health and treatment problems of burden of this disease (2).

The majority of breast tumors are asymptomatic and palpation of a lump count as common breast cancer symptoms. Breast tumor can appear as an abnormal pattern on mammogram study a few months prior to reach the state of being palpable by either physician or patient (3). 
Recent development in general awareness and educational levels, more screening mammography and therapeutic options resulted in enhanced early detection and overall survival rate of women diagnosed with breast cancer (4).

There are a few studies in the west countries that indicates that educational levels of breast cancer patients has a significant impact on prognosis because of more screening mammography in higher educational levels and earlier visiting by a physician after palpation of the tumor, thereby affecting the level of early detection, and then less pathological stage at surgery (5-8).

There is not any study in Iran can determine any association between educational levels and pathological stage at surgery, type of surgery (modified radical mastectomy (MRM) and breast conserving surgery (BCS)) and receiving more chemotherapy, radiotherapy and endocrine therapy among Iranian breast cancer patients.

\section{Objectives}

In this retrospective observational-descriptive, we compared educational background and its relationship to pathological stage and their treatment modalities among 3010 breast cancer patients at Cancer Research Center of the Shahid Beheshti University of Medical Sciences in February 2001 to December 2019.

\section{Materials And Methods}

In this retrospective observational-descriptive study, a consecutive series on patients with breast cancer (3010 patients) were extracted from the database at Cancer Research Center of the shahid beheshti University of Medical Sciences, a referral breast clinic in Tehran, Iran. Our sampling method was a timestratified approach to select of all 3010 women, with a pathological diagnosis of breast cancer were eligible for our study.

All 3010 breast cancer patients selected based on a time- stratified approach with stage I to IV (staging of breast cancer was categorized according to the American Joint Committee on Cancer (AJCC) TNM System of year 2016. All 3010 patients were categorized based on educational background in 6 levels: illiterate, primary school, middle school, high school and diploma, university and above and unspecified.

Our exclusion criteria were: Breast cancer patients who did not have acceptable follow up after initial diagnosis, patients who were without pathologic diagnosis. Our inclusion criteria were: Breast cancer patients with stage I to IV who had acceptable follow up after initial diagnosis and had at least 7 data of 14 baseline variables (age at diagnosis, marital status, family history of breast cancer, pathological stage of tumor, tumor histology, tumor grade, number of positive nodes, pathologic tumor size, chemotherapy, radiotherapy, endocrine therapy, ER, PR and HER2 status).

All breast cancer had pathologic diagnosis with was performed by biopsy or surgery of the primary breast tumor. From February 2001 to December 2019, with a median follow-up time was 71 months (range 48- 
192 months) all patients were recorded in data base. When all treatments were over, every breast cancer patient was visited and examined every 3 to 6 months for five years and yearly afterwards. The patients underwent annually mammography.

In the act provided by Shahid Beheshti University of Medical Sciences, the ethical regulations dictated were approved to review of the medical records for the purposes of our study (ethical code: IR.SBMU.MSP.REC.1396.358). Patient consent was not required for this study because there were no anticipated risks for the participants of the study.

Descriptive statistics were used to summarize the baseline characteristics, clinical-pathological features and educational level of 3010 adult patients with breast cancer and treatment modalities of the study population. Measurement data were expressed as mean \pm standard deviation (SD), and differences in all variables were evaluated and analyzed, by the Chi-square test.

Univariate logistic regression analysis was used for association between education level and pathological breast cancer stage, tumor size and treatment modalities in 3010 adult patients with breast cancer. Additionally, multivariate logistic regression analysis was used to explore for association between education level and breast cancer stage (stage I and stage II versus stages III and IV). A P value $<0.05$ was considered significant. All statistical analyses were performed, using the IBM SPSS 22.0.

\section{Results}

A consecutive series on patients with breast cancer (3010 patients) were extracted from the database at Cancer Research Center of the shahid beheshti University of Medical Sciences, the average age at diagnosis was 49.1 years \pm 11.6 .

The proportion of breast cancer patients' levels of education were $4.2 \%$ illiterate (126/3010), $7.8 \%$ primary school (233/3010), 7.5\% middle school (227/3010), 21.8\% high school and diploma (656/3010), $18.6 \%$ university and above (560/3010), and $40.1 \%$ unspecified (1208/3010).

2750 patients (91.4\%) had pathologic report of invasive ductal carcinoma, 220 patients (7.3\%) had invasive lobular carcinoma and 40 patients $(1.3 \%)$ had other pathology types except invasive ductal carcinoma and invasive lobular carcinoma respectively.

256 cases (8\%) had low differentiated grade, 1181 patients (39.2\%) had intermediate grade, 726 patients (24.1\%) had high grade and 847 cases $(28.2 \%)$ were with unknown grade respectively.

There was, 1133 patients (37.6\%) with zero involved lymph nodes, 498 patients (16.5\%) with 1-2 pathologic positive lymph nodes, 760 patients (25.3\%) with $\geq 3$ pathologic positive lymph nodes and 619 patients (20.6\%) with unspecified pathologic lymph nodes.

We had, 878 cases $(29.2 \%)$ with tumor $\leq 2$ centimeters $(\mathrm{cm}), 1425$ cases $(47.3 \%)$ with tumor size $2-5 \mathrm{~cm}$, 253 cases $(8.4 \%)$ with tumor size $>5$, and 454 cases $(15.1 \%)$ with unknown tumor size. 
Based on tumor stage, 491 cases (16.3\%) had stage I, 1352 cases (44.9\%) had stage II, 568 cases (18.7\%) had stage III, 83 cases $(2.7 \%)$ had stage IV and 516 patients $(17.1 \%)$ were with unspecified stage.

There were in 3010 for patients for ER status: 1496 (49.7\%) patients had ER positive, 629 cases (20.9\%) were ER negative and 885 (29.4\%) cases were with unspecified ER receptor status.

For PR status, there was, 1413 (46.9\%) patients, 712 (23.7\%) patients and 885 (29.4\%) patients with PR positive, PR negative and unknown PR receptor status respectively.

There were in all patients, 701 patients (23.3\%), 1808 patients $(60.1 \%)$ and 501 patients (16.6\%) with HER 2 positive, HER 2 negative and unspecified HER 2 status respectively.

Table 1 summarizes baseline characteristics, clinical-pathological features and educational level of 3010 adult patients with breast cancer

As of December 2019, a median follow-up time was 71 months (range 48-192 months), 1092 cases (36.3\%) underwent MRM, 1580 patients (52.5\%) underwent BCS and 338 patients (11.2\%) were with unspecified surgery.

In all patients, 161 cases $(5.4 \%)$ received NAC, 1625 patients $(54 \%)$ received AC, 40 cases $(1.3 \%)$ did not receive any chemotherapy and 1184 patients (39.3\%) were with unspecified chemotherapy.

In 3010 cases, 1927 cases (64\%) received radiotherapy, 61 cases (2\%) did not receive any radiotherapy and 1022 patients (34\%) were with unspecified radiotherapy.

There were in 3010 patients, 1596 cases (53\%) received endocrine therapy, 1143 cases (38\%) did not receive any endocrine therapy and 271 patients (9\%) were with unspecified endocrine therapy.

Table 2 summarizes treatment modalities of 3010 adult patients with breast cancer.

Based on univariate logistic regression analysis, the illiterate group had $65.1 \%$ of early stage breast cancer (stage I and stage II), and the university and above group had $73.4 \%$ of early stage breast cancer (p-value<.001). Conversely the highest rate of pathological advanced breast cancer (stage III and stage IV), was found within the illiterate group (31.7\%) and the lowest was university and above group (17.6\%) ( $p$-value<.001). Thus different education backgrounds had a significant impact on final pathological staging distribution.

There were no significant differences in tumor size for the illiterate group who had $34.2 \%$ of tumor size $\leq 2 \mathrm{~cm}$ and the university and above group who had $29.5 \%$ of tumor size $\leq 2 \mathrm{~cm}$ and the rate of tumor size $>5 \mathrm{~cm}$, was found within the illiterate group (6.3\%) and was lower than the university and above group $(8.2 \%)(p-v a l u e=0.145)$. Thus different education backgrounds did not have a significant impact on final tumor size distribution. 
The rate of MRM in the illiterate group, the primary school, the middle school, the high school and diploma and the university and above group was $73.8 \%, 70.8 \%, 72.7 \%, 46.4 \%$, and $15.9 \%$ respectively. The rate of BCS in the illiterate group, the primary school, the middle school, the high school and diploma, and the university and above group was $15.1 \%, 18 \%, 16.3 \%, 42.5 \%$, and $73.2 \%$ respectively. Based on univariate logistic regression analysis, these differences were significant ( $p$-value<.001). Thus patients with higher education took BCS and patients with lower education took MRM.

According to univariate logistic regression analysis, $35.7 \%, 69.1 \%, 75.4 \%, 80 \%$, and $93.7 \%$ of the illiterate group, the primary school, the middle school, the high school and diploma, and the university and above group received chemotherapy in their treatment modalities respectively ( $p$-value<.001). These differences were significant. Thus patients with higher education received more chemotherapy than patients with lower education, in in their treatment modalities.

There was shown: $42.1 \%, 54.5 \%, 60.3 \%, 70.7 \%$, and $64.3 \%$ in the illiterate group, the primary school, the middle school, the high school and diploma, and the university and above group receiving radiotherapy in their treatment modalities respectively(p-value<.001). Thus patients in the university and above group received more radiotherapy than patients within the illiterate and the primary school group in in their treatment modalities.

We also found: $50 \%, 64 \%, 69.2 \%, 70 \%$, and $71.1 \%$ in the illiterate group, the primary school, the middle school, the high school and diploma, and the university and above group receiving endocrine therapy in their treatment modalities respectively(p-value<.001). Thus patients with higher education received more endocrine therapy than patients with lower education, in in their treatment modalities. These differences were significant, based on univariate logistic regression analysis.

Table 3 summarizes univariate logistic regression analysis for association between education level and pathological breast cancer stage, tumor size and treatment modalities in 3010 adult patients with breast cancer.

Based on univariate logistic regression analysis education backgrounds had a significant impact on final pathological staging distribution. To prove whether education background of breast cancer patients was an independent factor, that affecting final pathological tumor stage, we rounded a multivariate analysis with a total of 2494 cases this time ((1843 early stages (stage I and stage II) versus 651 advanced stages (stages III and IV)).

Based on multivariable logistic regression analysis, there was not a significant correlation between middle and high school vs. primary school and below and final pathological tumor stage with odds ratio $=0.83$ and $95 \%$ confidence interval $(0.62-1.11)$ ( $p$-value $=0.2)$. The results suggested that education level with middle and high school vs. primary school and below was not an independent protective factor

According to multivariable logistic regression analysis, there was a significant correlation between university and above group versus primary school and below group and final pathological tumor stage 
with odds ratio $=0.57$ and $95 \%$ confidence interval $(0.35-0.93)$ ( $p$-value $=0.02)$. The results suggested that education level was an independent factor that affecting final pathological tumor stage. Compared with primary education and below, University and above education was an independent protective factor.

Table 4 summarizes multivariable logistic regression for association between education level and breast cancer stage (stage I and stage II versus stages III and IV).

\section{Discussion}

The aim of our study showed that university and above group had more early stage breast cancer and less advanced stage breast cancer compare to primary school and below group based on univariate and multivariable logistic regression analysis. In the current study, with has been conducted at Cancer Research of the Shahid Beheshti University, we also showed, patients in higher education groups received more chemotherapy, radiotherapy and endocrine therapy than patients with lower education groups in in their treatment modalities among total 3010 patients, and to the best of our knowledge, is the greatest series in Iran.

Macleod et al who study showed a higher rate of clinically locally advanced breast cancer patients in low educational groups than high educational groups(p-value=0.01)(9). These findings were consistent with our study with has been shown, that university and above group had more early stage breast cancer and less advanced stage breast cancer compare to primary school and below group.

Brewster et al reported no significant differences in clinical stage among socioeconomic and educational groups, These findings were inconsistent with our study with found that patients in higher education groups had less pathological advanced breast cancer than patients with lower education groups. They also found increasing tumor size in lower education groups than patients in higher education groups $(p=0.02)(10)$. These findings were also inconsistent with our study with found that patients in lower education groups did not have increasing tumor size than patients in higher education background group (p-value=0.145).

Montazeri et al showed patients in illiterate (OR 5.7, 95\% $\mathrm{Cl} 1.9-16.5)$ and primary educated group (OR $4.2,95 \% \mathrm{Cl} 1.5-12.1$ ) had delay in diagnosis and more advanced stage than secondary and higher education group (11). These findings were consistent with our study that showed the highest rate of pathological advanced breast cancer, was found within the illiterate group $(31.7 \%)$ and the lowest was university and above group $(17.6 \%)(\mathrm{p}<.001)$.

Grunfeld et al found patients in poor educated group had delay in diagnosis and more advanced stage than patients in well educated group $\left(X^{2}=46.11, d f=4, p<.001\right)(12)$. These findings were consistent with our study that showed the lowest rate of pathological advanced breast cancer, was found in well educated group (17.6\%) and the highest rate of pathological advanced breast cancer was found in poor educated group $(31.7 \%)(\mathrm{p}<.001)$. 
In our study, we also found that there were significant differences among breast cancer patients with different education backgrounds regarding their choice of surgery types, in the highest education group, the rate BSC was highest, meanwhile, in the lowest education group, the rate MRM was highest $(\mathrm{p}<.001)$. These findings were also consistent with Yang Liu et al study with found that patients in lower education groups, took more MRM and less BCS, than patients in higher education background group ( $p<.001)(13)$.

Yang Liu et al study also showed patients in higher education groups received more chemotherapy, radiotherapy and endocrine therapy than patients with lower education groups in in their treatment modalities $(p<.001)$. These findings were consistent with our study that showed patients in higher education groups received more chemotherapy, radiotherapy and endocrine therapy than patients with lower education groups( $\mathrm{p}<.001)$.

Wang et al found increasing tumor size in lower education groups than patients in higher education groups $(p=0.049)(14)$. These findings were also inconsistent with our study with found that patients in lower education groups did not have increasing tumor size than patients in higher education background group ( $p$-value=0.145). They also showed patients in higher education groups received more chemotherapy, radiotherapy and endocrine therapy than patients with lower education groups in in their treatment modalities ( $p<.001, p=0.017, p=0.031$ respectively). These findings were consistent with our study that showed patients in higher education groups received more chemotherapy, radiotherapy and endocrine therapy than patients with lower education groups $(p<.001)$.

The limitations of this study included the missing data of some patients' information and the short follow up period.

\section{Conclusions}

The findings of this study showed that education background have a significant impact on pathological staging and the selection of treatment modalities. These results suggest that the ministry of health should focus on lower educational group to develop more screening mammography prevention and treatment strategies for breast cancer in this group.

\section{Declarations}

\section{Funding/Support}

The authors received no financial support for the research, authorship, and/or publication of this article.

\section{Conflict of Interest}

There is no conflict of interest to be declared.

\section{References}


1. DeSantis C, Ma J, Bryan L, Jemal A. Breast cancer statistics, 2013. CA: a cancer journal for clinicians. 2014 Jan; 64(1):52-62.

2. Goya M. Iranian Annual Cancer Registration Report 2015/2016. Ministry of Health and Medical Education, Health Deputy, Center for Disease Control and Prevention (In Persian). Tehran, Iran, 2007.

3. Atkins $\mathrm{H}$, Hayward JL, Klugman DJ, et al. Treatment of early breast cancer: a report after ten years of a clinical trial. Br Med J 1972; 2:423-9. https://doi.org/10.1136/bmj.2.5811.423

PMid:4624222 PMCid:PMC1788035

4. Macleod U, Ross S, Gillis C, et al. Socio-economic deprivation and stage of disease at presentation in women with breast cancer. Ann Oncol 2000; 11:105-7.

5. Anderson BO, Jakesz R (2008). Breast cancer issues in developing countries: an overview of the Breast Health, Global Initiative. World J Surg, 32, 2578-85.

6. Richardson JL, Langholz B, Bernstein L, et al (1992). Stage and delay in breast cancer diagnosis b1y race, socioeconomic status, age and year. Br J Cancer, 65, 922-6

7. Barry J, Breen $\mathrm{N}$. The importance of place of residence in predicting late-stage diagnosis of breast or cervical cancer. Health Place 2005; 11:15-29.

8. Ramirez AJ, Westcombe AM, Burgess CC, Sutton S, Littlejohns P, Richards MA (1999) Factors predicting delayed presentation of symptomatic breast cancer: a systematic review. The Lancet 353: $1127-1131$

9. Macleod U, Ross S, Gillis C, et al. Socio-economic deprivation and stage of disease at presentation in women with breast cancer. Ann Oncol

$2000 ; 11: 105-7$.

10. Brewster DH, Thomson CS, Hole DJ, Black RJ, Stroner PL, Gillis CR. Relation between socioeconomic status and tumour stage in patients with breast, colorectal, ovarian, and lung cancer: results from four national, population based studies. BMJ. 2001 Apr 7;322(7290):830-1. doi: 10.1136/bmj.322.7290.830. PMID: 11290637; PMCID: PMC30560.

11. Montazeri, A., Ebrahimi, M., Mehrdad, N. et al. Delayed presentation in breast cancer: a study in 
Iranian women. BMC Women's Health 3, 4 (2003). https://doi.org/10.1186/1472-6874-3-4

12. Grunfeld, E., Ramirez, A., Hunter, M. et al. Women's knowledge and beliefs regarding breast cancer. Br J Cancer 86, 1373-1378 (2002). https://doi.org/10.1038/sj.bjc.6600260

13. Liu, Yang et al. "Influence of occupation and education level on breast cancer stage at diagnosis, and treatment options in China: A nationwide, multicenter 10-year epidemiological study." Medicine vol. 96,15 (2017): e6641. doi:10.1097/MD.0000000000006641.

14. Wang, Ke, et al. "Socio-Economic Factors Influencing Tumor Presentation and Treatment Options in Chinese Breast Cancer Patients." Asian Pacific Journal of Cancer Prevention, vol. 14, no. 1, Asian Pacific Organization for Cancer Prevention, Jan. 2013, pp. 267-274. Crossref, doi:10.7314/apjcp.2013.14.1.267

\section{Tables}

Table 1. Baseline characteristics, clinical-pathological features and educational level of 3010 adult patients with breast cancer 


\begin{tabular}{|c|c|c|}
\hline \multicolumn{2}{|l|}{ Characteristics } & \multirow{2}{*}{$\begin{array}{l}\text { Value (\%) } \\
0(0)\end{array}$} \\
\hline Gender & Male & \\
\hline & Female & $3010(100)$ \\
\hline \multicolumn{2}{|c|}{ Average age at diagnosis (years) } & $49.1 \pm 11.6$ \\
\hline \multirow{6}{*}{ Education } & University and above & $560(18.6)$ \\
\hline & High school and Diploma & $656(21.8)$ \\
\hline & Middle school & $227(7.5)$ \\
\hline & Primary school & $233(7.8)$ \\
\hline & Illiterate & $126(4.2)$ \\
\hline & Unspecified & $1208(40.1)$ \\
\hline \multirow[t]{4}{*}{ Family history of breast cancer } & None & $1400(46.5)$ \\
\hline & First degree & $106(3.5)$ \\
\hline & Second degree & $205(6.8)$ \\
\hline & Unspecified & $1299(43.2)$ \\
\hline \multirow[t]{3}{*}{ Marital Status } & Married & $1956(65)$ \\
\hline & Single & $124(4.1)$ \\
\hline & Unspecified & $930(30.9)$ \\
\hline \multirow{3}{*}{ Hsiotological type } & Invasive ductal carcinomas & $2750(91.4)$ \\
\hline & Invasive lobular carcinomas & $220(7.3)$ \\
\hline & Others types & $40(1.3)$ \\
\hline \multirow[t]{4}{*}{ Tumor size } & $\leq 2 \mathrm{~cm}$ & $878(29.2)$ \\
\hline & $2-5 \mathrm{~cm}$ & $1425(47.3)$ \\
\hline & $>5 \mathrm{~cm}$ & $253(8.4)$ \\
\hline & Unspecified & $454(15.1)$ \\
\hline \multirow[t]{4}{*}{ Grade } & low & $256(8.5) \quad 10$ \\
\hline & Intermediate & $1181(39.2)$ \\
\hline & High & $726(24.1)$ \\
\hline & Unspecified & $847(28.2)$ \\
\hline \multirow[t]{3}{*}{ Lymphovascular invasion } & Positive & $1204(40)$ \\
\hline & Negative & $864(28.7)$ \\
\hline & Unspecified & $942(31.3)$ \\
\hline \multirow[t]{4}{*}{ Number of involved Lymph nodes } & None & $1133(37.6)$ \\
\hline & 1-2 involved Lymph nodes & $498(16.5)$ \\
\hline & $\geq 3$ & $760(25.3)$ \\
\hline & Unspecified & $619(20.6)$ \\
\hline \multirow[t]{5}{*}{ Stage } & Stage I & $491(16.3)$ \\
\hline & Stage II & $1352(44.9)$ \\
\hline & Stage III & $568(18.7)$ \\
\hline & Stage IV & $83(2.7)$ \\
\hline & Unspecified & $516(17.1)$ \\
\hline \multirow[t]{3}{*}{ Estrogen Receptor } & Positive & $1496(49.7)$ \\
\hline & Negative & $629(20.9)$ \\
\hline & Unspecified & $885(29.4)$ \\
\hline \multirow[t]{3}{*}{ Progesterone Receptor } & Positive & $1413(46.9)$ \\
\hline & Negative & $712(23.7)$ \\
\hline & Unspecified & $885(29.4)$ \\
\hline \multirow[t]{3}{*}{ Her2 status } & Her2+ & $701(23.3)$ \\
\hline & Her2- & $1808(60.1)$ \\
\hline & Unspecified & $501(16.6)$ \\
\hline \multicolumn{2}{|l|}{ Total patients } & $3010(100)$ \\
\hline
\end{tabular}

Table 2. Treatment modalities of 3010 adult patients with breast cancer 


\begin{tabular}{|l|l|l|}
\hline Characteristics & Value (\%) \\
\hline \multirow{4}{*}{ Surgery } & Modified radical mastectomy & $1092(36.3)$ \\
\cline { 2 - 3 } & Breast conserving surgery & $1580(52.5)$ \\
\cline { 2 - 3 } & Unspecified & $338(11.2)$ \\
\hline \multirow{5}{*}{ Chemotherapy } & Neoadjuvant chemotherapy & $161(5.4)$ \\
\cline { 2 - 3 } & Adjuvant chemotherapy & $1625(54)$ \\
\cline { 2 - 3 } & Without chemotherapy & $40(1.3)$ \\
\cline { 2 - 3 } & Unspecified & $1184(39.3)$ \\
\hline Radiotherapy & Done & $1927(64)$ \\
\cline { 2 - 3 } & Not done & $61(2)$ \\
\cline { 2 - 3 } & Unspecified & $1022(34)$ \\
\hline Endocrine therapy & Done & $1143(53)$ \\
\cline { 2 - 3 } & Not done & $271(9)$ \\
\cline { 2 - 3 } & Unspecified & $3010(100)$ \\
\hline Total patients & & \\
\hline
\end{tabular}

Table 3. Univariate logistic regression analysis for association between education level and pathological breast cancerstage, tumor size and treatment modalities in 3010 adult patients with breast cancer.

\begin{tabular}{|c|c|c|c|c|c|c|c|}
\hline Characteristics & $\begin{array}{l}\text { Illiterate } \\
(126)\end{array}$ & $\begin{array}{l}\text { Primary } \\
\text { school (233) }\end{array}$ & $\begin{array}{l}\text { Middle } \\
\text { school } \\
(227)\end{array}$ & $\begin{array}{l}\text { High school and } \\
\text { Diploma(656) }\end{array}$ & $\begin{array}{l}\text { University and } \\
\text { above (560) }\end{array}$ & $\begin{array}{l}\text { Unspecified } \\
(1208)\end{array}$ & $\begin{array}{l}\mathrm{p}- \\
\text { value }\end{array}$ \\
\hline \multicolumn{6}{|l|}{ Surgery } & \multicolumn{2}{|l|}{$<.001$} \\
\hline $\begin{array}{l}\text { Modified } \\
\text { radicalmastectomy }\end{array}$ & $93(73.8)$ & $165(70.8)$ & $165(72.7)$ & $304(46.4)$ & $89(15.9)$ & 447 (37) & \\
\hline $\begin{array}{l}\text { Breast } \\
\text { conserving surgery }\end{array}$ & $19(15.1)$ & $42(18)$ & $37(16.3)$ & $279(42.5)$ & $410(73.2)$ & $628(52)$ & \\
\hline Unspecified & $14(11.1)$ & $26(11.2)$ & $25(11)$ & $73(11.1)$ & $61(10.9)$ & $133(11)$ & \\
\hline \multicolumn{6}{|l|}{ Chemotherapy } & \multicolumn{2}{|l|}{\begin{tabular}{l|l} 
& 0.025 \\
\end{tabular}} \\
\hline Done & $45(35.7)$ & $161(69.1)$ & $171(75.4)$ & $525(80)$ & $525(93.7)$ & $498(41.2)$ & \\
\hline Not done & $2(1.6)$ & $3(1.3)$ & $3(1.3)$ & $6(0.9)$ & $5(0.9)$ & $18(1.5)$ & \\
\hline Unspecified & $79(62.7)$ & $69(29.6)$ & $53(23.3)$ & $125(19.1)$ & $30(5.4)$ & $692(57.3)$ & \\
\hline \multicolumn{6}{|l|}{ Radiotherapy } & \multicolumn{2}{|l|}{\begin{tabular}{l|l} 
& $<.001$ \\
\end{tabular}} \\
\hline Done & $53(42.1)$ & $127(54.5)$ & $137(60.3)$ & $464(70.7)$ & $360(64.3)$ & $578(47.8)$ & \\
\hline Not done & $13(10.3)$ & $13(5.6)$ & $27(11.9)$ & $101(15.4)$ & $64(11.4)$ & $178(14.8)$ & \\
\hline Unspecified & $60(47.6)$ & 93 (39.9) & $63(27.8)$ & $91(13.9)$ & $136(24.3)$ & $452(37.4)$ & \\
\hline \multicolumn{6}{|l|}{ Endocrine therapy } & \multicolumn{2}{|l|}{\begin{tabular}{l|l} 
& $<.001$ \\
\end{tabular}} \\
\hline Done & $63(50)$ & $149(64)$ & $157(69.2)$ & $459(70)$ & $398(71.1)$ & $595(49.3)$ & \\
\hline Not done & $42(33.4)$ & $70(30)$ & $56(24.7)$ & $181(27.6)$ & $137(24.5)$ & 405 (33.5) & \\
\hline Unspecified & $21(16.6)$ & $14(6)$ & $14(6.1)$ & $16(2.4)$ & $25(4.4)$ & $208(17.2)$ & \\
\hline \multicolumn{6}{|l|}{ Tumor size } & \multicolumn{2}{|l|}{0.145} \\
\hline$\leq 2 \mathrm{~cm}$ & $43(34.2)$ & $79(33.9)$ & $67(29.5)$ & $193(29.4)$ & 165 (29.5) & $329(27.2)$ & \\
\hline $2-5 \mathrm{~cm}$ & 55 (43.6) & 106 (45.5) & 99 (43.6) & 299 (45.7) & $224(40)$ & $604(50)$ & \\
\hline$>5 \mathrm{~cm}$ & $8(6.3)$ & $19(8.2)$ & $19(8.4)$ & $66(10)$ & $46(8.2)$ & $102(8.5$ & \\
\hline Unspecified & $20(15.9)$ & $29(12.4)$ & $42(18.5)$ & $98(14.9)$ & $85(15.3)$ & $173(14.3)$ & \\
\hline \multicolumn{6}{|l|}{ Stage } & \multicolumn{2}{|l|}{\begin{tabular}{l|l|} 
& $<.001$
\end{tabular}} \\
\hline Stage I and II & $82(65.1)$ & $152(65.3)$ & $151(66.5)$ & $433(66)$ & $411(73.4)$ & $725(60)$ & \\
\hline Stage III and IV & $40(31.7)$ & $63(27)$ & $57(25.1)$ & $162(24.7)$ & 99 (17.6) & $240(19.9)$ & \\
\hline Unspecified & $4(3.2)$ & $18(7.7)$ & $19(8.4)$ & $61(9.3)$ & $50(9)$ & $243(20.1)$ & \\
\hline
\end{tabular}

$\mathrm{ER}=$ estrogen receptor, Her2 = human epidermal growth factor receptor 2, PR = progesterone receptor. 
Table4. Multivariable logistic regression for association between education level and breast cancer stage (stage I and stage II versus stages III and IV).

\begin{tabular}{|l|l|l|l|l|}
\hline \multirow{2}{*}{ Factor } & \multicolumn{4}{l|}{ Multivariate analysis } \\
\cline { 2 - 5 } & Coefficient & $\mathrm{SE}^{\mathrm{c}}$ & $\mathrm{OR}^{\mathrm{a}}\left(95 \% \mathrm{CI}^{\mathrm{b}}\right)$ & $\mathrm{p}$-value \\
\hline Age at diagnosis years & -0.003 & 0.007 & $0.99(0.98-1.01)$ & 0.64 \\
\hline Middle and high school vs. primary schooland belov & -0.19 & 0.15 & $0.83(0.62-1.11)$ & 0.20 \\
\hline University and above vs. primary schooland below & -0.55 & 0.25 & $0.57(0.35-0.93)$ & 0.02 \\
\hline
\end{tabular}

a OR: odds ratio; ${ }^{\mathrm{b}} \mathrm{CI}$ : confidence interval; ${ }^{\mathrm{c} S E}$ : standard error 